\title{
A teoria da Ação Comunicativa de Jürgen Habermas: Conceitos Básicos e Possibilidades de Aplicação à AdMINISTRAÇÃo Escolar
}

Joscí Marcelino de Rezende P'inco*

RESUMO

Neste trabalho buscaremos apresentar uma síntese dos principais conccilos da tcoria da ação comunicaliva de Jürgen l labermas assim como deduzir algumas de suas implicações para o esludo das organizações. Em parlicular, buscarcmos mostrar que esla leoria se conslilui em poderoso instrumento analílico no estudo da estrulura e funcionamento dos conselhos com participação popular que são uma marca caracleríslica das sociedacles capilalistas contemporâneas. Este estudo lem por base a lese de doutorado Administraģ̃o e Liberdade: Um estudo do Consclho de Escola à luz da leoria da aşào comunicaliva de Jürgen l tabermas ( Pinto, 1994).

\section{INTRODUÇÃO}

Um primeiro alerta que deve ser feilo quando nos iniciamos no eslude das idéias de Habermas é que, muilo embora ele se configure como um legílimo representante do movimento que se convencionou chamar Escola de Frankfurt, como apontam McCarthy (1984) e Persson (1992), no perspecliva da abordagem habermasiana o esludo da sociedade deve inciuir e; sempre que possível, integrar enfoques leóricos divergentes. Em virtiole desta postura, l labermas desenvolve sua leoria da ação comunicaliva em um diálogo constante com autores de uma ampla gama de linhas teóricas. Assim, ele incorpora uma série de lemas e contribuiçées que foram desenvolvidos, scja pelo funcionalismo, pela fenomenologia, pelo maxismo, ou pela própria leoria crílica da escola de Frankfurl, sua malriz original e mais imporLanle. Desta forma, sua leoria assume naluralmenle um caráler inlerparadigmálico, o que não significa, como veremos, um mero amálgama de várias linhas teóricas mas um processo extremamente rico de incorporaک̧̃̃o/superação.

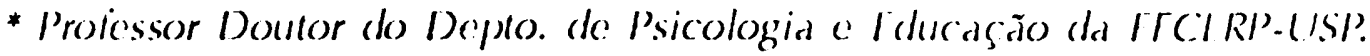




\section{AçÃo Comunicativa e Mundo da Vida}

Jürgen I tabermas scrá o aulor que buscará enfrentar os tantasmas deteclados por Wober, Adorno e llorkheimer nos processos de racionalização sociclária. Estes autores mostraram em suas análises, o processo pelo qual o Iluminismo que, na forma da razão cientílica, surgiu no séce. XVIII como o grande agente de liberlaçio social, de conquista da maioridade pelo ser humano, de destruição dos mitos, fransioma-se ele próprio em um novo mito e consolida-se enquanto ideologia de dominação que legilima a sociedade capitalista. A dominação do homem sobre a nature/a, converte-se em dominação do homem sobre o homem, em mundo administrado em nome da lécnica, abrindo espaço para a ectesão da des-razão no secio da sociedade de consumo moldeda pela indústria cultural. Para l labermas, a análise destes autores chega a um impasse porque eles trabalham com um conceito restrito de razão. Em virtude disto, des confundem o processo de modernização capilalista, que é calcado na razão instrumental, como senclo a própria racionalização societária (labermas, 1987a). Agindo desta forma, confundindo racionalidade do sistema com racionalidade da ação, estes autores só conseguiram siluar a espontancidade livre de reificação em poderes irracionais como o carisma, no (aso de Weber, a arte, para Adomo e o amor, para Horkheimer.

Para sair deste impasse, I labermas propoe um salto paradigmático, no qual abandona-se o paradigma da consciência a que estes autores ancontram-se presos, em prol de um paradigma da comunicação. O paradigma da consciência é calcado na idéia de um pensader solitário que busca entender o munde a sua volla, descobrindo as leis gerais que o governam, revelando a unidade encoberta sob) a diversidade aparente. Neste modelo há uma relação de subordinação do ob jeto frente ao sujeito. Para l labermas, este paradigma não se sustenta mais.1)epois que I legel mostrou o Caráter intrinsecamente social e histórico das estruluras da consciencia, que Marx revelou que a mente não é o campo da natureza, mas o inverso e que as formas de consciencia são representações ocultas das iomas de reprodução social; depois que Darwin estabeleceu o vínculo entre inteligência e sobrevivência e, linalmente, que Nickache e Freud revelaram o inconsciente no âmago da consciência, dá-se uma dessublimą̧ão do espírito e um enfraquecimento da bilosolia (McCarthy, 1984). O pensamento filosólico perde sua auto-suliciência, caem as esperanças de se encontrar os fundamento últimes de uma primeira filosoliar.

Como abirma labermas,

...ecupretendo arguir que uma mudança de paradigma para o da leoria da comunicaşäo lomará possivel um relorno à larefa que foi interrompida com a crítica da razäo instrumental; e. isto nos permilirá relomar as larclas, desde enlão negligenciddas, de uma leoria crílica da sociedade(19884, p. 386). 
Distintamente do que ocorre com a filosofia da consciência, o que é paradigmático para a racionalidade comunicativa

...não é a relação de um sujeito solitário com algo no mundo objetivo que pode ser representado e manipulado mas a relação intersubjetiva, que sujeitos que falam e atuam, assumem quando buscam o entendimento entre si, sobre algo . Ao fazer isto, os atores comunicativos movem-se por meio de uma linguagem natural, valendo-se de interpretações culturalmente transmitidas e referem-se a algo simultaneamente em um mundo objetivo, em seu mundo social comum e em seu próprio mundo subjetivo(1984, p. 392).

Esta mudança de paradigma é fruto do abandono de uma compreensão egocêntrica do mundo, cuja fundamentação Habermas retira do conccito de descentração de Piaget .

Habermas buscará então, a partir de um diálogo com Marx, Weber, Durkheim, Mead, Lukács, Horkheimer, Adorno, Marcuse e Parsons, pensando com eles para ir além deles como esclarece McCarthy (1984), construir um conceito de racionalidade que encontra seus fundamentos nos processos de comunicação intersubjetiva com vistas a alcançar o entendimento.Segunclo Aragão (1992, p. 82),

... Habermas acredita que, na estrutura da linguagem cotidiana, está embutida uma exigência de racionalidade pois, com a primeira frase proferida, o homem já manifestava uma pretensão de ser compreendido, uma busca de entendimento .

Esta razão distingue-se completamente da razão instrumental, a qual estrutura-se no uso não comunicativo do saber em ações dirigidas a fins. A racionalidade instrumental que, através do empirismo, marcou profundamente a autocompreensão da era moderna foi submetida à crítica implacável de Weber e posteriormente de Adorno, Horkheimer e Marcuse. O grande problema destas abordagens é que, nelas, eles confundiram um tipo particular de racionalização e suas consequências como sendo patologias da própria razão .

Portanto, com a constatação da inexistência de um referencial teórico absoluto e com os limites demonstrados do empirismo, o que torna melhor um argumento é "a sonoridade de suas razões" (Habermas, 1984, p. 24).Por sua vez, o que caracteriza a racionalidade de uma expressão linguística é o fato de suas pretensões de validade serem suscelíveis à crílica, através de procedimentos reconhecidos intersubjetivamente .Por outro lado, para Habermas, em um processo de comunicação mediado linguisticamente, existem somente três critérios de alcance universal pelos quais as pretensões de validade podem ser confrontadas.

Assim, as pretensões de validade podem ser criticáveis quanto à :

1- Veracidade da afirmação. Esta pretensão refere-se a um mundo objetivo entendido como a totalidade dos fatos cuja existência pode ser verificada;

2- Correção normativa. Esta pretensão refere-se a um mundo social dos 
atores, entendido como a totalidade das relações interpessoais que são legitimamente reguladas;

3- Autenticidade e sinceridade.Esta pretensão refere-se a um mundo subjetivo, entendido como a totalidade das experiências do locutor às quais, em cada situação, apenas ele tem acesso privilegiado(Habermas, 1984).

O conceito de razão comunicativa de Habermas pressupõe, portanto, uma diferenciação entre os mundos objetivo, social e subjetivo. Esta diferenciação, segundo ele, é que distingue o pensamento moderno do modo de pensar mítico.Ao contrário do último, o primeiro assume que as interpretações variam com relação à realidade social e natural e que as crenças $e$ valores variam em relação ao mundo objetivo e social .

Outra consequência deste conceito é que ele pressupõe o abandono da relação cognitiva sujeito-objeto por um procedimento cognitivo de natureza intersubjetiva, numa relação sujeito-outro sujeito e que só é possivel com a progressiva descentração de nossa visão egocêntrica de mundo .

Portanto, com a superação da visão mítica com seu caráter unificador e com o abandono da relação sujeilo solitário dominante e consciente frente a um objeto dominado e cognoscivel, surge a necessidade dos atores em comunicação chegarem ao entendimento quanto a pretensões de validade críticáveis.Fica então, também, demarcada a diferença entre ação comunicativa e ação orientada para o sucesso. Como diz Habermas, a ação comunicativa ocorre

...sempre que as ações dos agentes envolvidos são coordenadas, não através de cálculos egocêntricos de sucesso mas através de alos de alcançar o entendimenlo (grifo nosso). Na ação comunicativa, os participantes não estão orientados primeiramente para o seu próprio sucesso individual, eles buscam seus objelivos individuais respeitando a condição de quepodem harmonizar seus planos de ação sobre as bases de uma definição comum de siluação.Assim, a negociação da definição de siluação é um elemento essencial do complemento interpretativo requerido pela ação comunicaliva $(1984$, p. 285, 286).

Em síntese, podemos dizer então que, para Habermas, a ação comunicativa surge como uma interação de, no mínimo dois sujcitos, capazes de falar e agir, que estabelecem relações interpessoais com o objetivo de alcançar uma compreensão sobre a siluação cın que ocorre a interação e sobre os respectivos planos de ação com vistas a coordenar su is ações pela via do entendimento. Neste processo, eles se remetem a prutensões de validade criticáveis quanto à sua veracidade, correção normaliva e autenticidade, cada uma destas pretensões referindo-se respectivamente a um mundo objelivo dos fatos, a um mundo social das normas e a um munclo das experiências subjetivas .Para construção deste conceito, ele se baseou no interacionismo simbólico de Mead, no conceito de jogos de linguagem de Willgenstein, na teoria dos atos de fala de Austin e na hermenêulica de Gadamer . 
O conceito de alcançar o entendimento que decorre da ação comunicaliva requer, por sua vez, a definição do contexto em que estes procedimentos acontecem. Isto porque aquilo que o falante quer dizer com seu pronunciamento depende do conhecimento acumulado e realiza-se sob o pano de fundo de um consenso cullural anterior .É neste ponto que llabermas introduz o conceito de mundo da vida (Lebenswelt), entendido como o conlexto não problematizável, o pano de fundo que propicia os processos de se alcançar o entendimento. Como de afirma, no sentido colidiano o mundo da vida pode ser entendido como aquele em que"os atores comunicalivos siluam e datam seus pronunciamenlos em espaços sociais e lempos históricos" (1987a, p. 136). Ele é constiluído por um saber implícilo sobre o qual nós, normalmente, nada sabemos porque ele é simplesmente não problemático, não alinge o limiar dos pronunciamentos comunicativos que podem ser válidos ou não. Como ele escreve,

...se a verdade é o que é fundamentado, então o fundamento não é verdadeiro, ou falso(1987a, p. 337). ( Mesmo porque J, os alores estão sempre se movendo dentro do horizonle do scu mundo da vida, eles não podem se colocar de fora dele. Como intérpreles, cles próprios pertencem ao mundo da vida, por meio de scus alos de fala, mas não podem se referir a "algo no mundo da vida" da mesma forma que podem fazer com falos, normas e exporicincias subjelivas(1987a, 1). 12.5, 126).

O mundo da vida por sua vez é dividido em três componentes estrulurais: Cullura, sociedade e pessoa.

- Cullura, entendida como o estoque de conhecimento do qual os atores suprem-se de interpretações quando buscam a comprecnsão sobre algo no mundo;

-Sociedade, entendida como as ordens legílimas allavés das quais os parlicipantes regulam suas relações no grupo social;

- Pessoa, entendida como as competencias que tornam um sujeito capaz de falar e agir, ou seja, de compor sua própria personalidade (1 labermas, $1987 a)$.

Para l labermas, existe uma correlação dircta entre ação comunicaliva e mundo da vida, já que cabe à primeira a reprodução das estruluras simbólicas do segundo (cultura, sociedacle, pessoa). Assim, sol) o aspecto do entendimento múluo, a ação comunicaliva serve para transmilir e renovar o saber cullural; sob o aspecto de coordenar a ação, cla propicia a integração social; e sob o aspecto da socializaşào, cla serve a formação da porsonalidade individual.

Por outro lado, a reprodução do substrato material do mundo da vida ocorre alravés de açõos dirigidas a fins pelos quais os indivíduos associados intervêm no mundo e realizam seus objetivos.

Estabelecidos os conceitos complementares de ação comunicativa e de mundo da vida, partiremos agora para a análise da leoria da evolução social de llabermas, a partir da qual cle fundamenta o seu conceilo do soci- 
edade, assim como os limites e possibilidades da utopia comunicativa, advindos com os estágios mais avançados do desenvolvimento capilalista.

\section{UMA TEORIA DA MODERNIDADE}

Para construir sua teoria da evolução social e seu conceito de sociedade, I Tabermas busca articular as abordagens de H. Mead e E. Durkheim. Deste, retira a idéia de um Estado limite, totalmente integrado, enquanto do primeiro incorpora a tese do efeito desintegrador que os atos de fala desencadeiam quando a reprodução simbólica do mundo da vida está liģada à ação comunicaliva. Estes atos provocam uma racionalização do mundo da vida dos grupos sociais, à medida em que a linguagem preenche as funções de alcançar o entendimento, coordenar ações e socializar os indivícluos(1-tabermas, 1987a).

Habermas, loma como ponto de partida, a idéia de Durkheim de uma situação hipotética inicial, na cqual existe uma sociedade totalmente integrada, cuja coesão social é assegurada pelos domínios do sagrado e onde não é necessária a mediação da linguagem tanto nos domínios religiosos quanto profanos. A religião assegura a unidade da colelividade e reprime os conflitos que podem surgir nas relações de poder ou nos interesses econômicos. Isto representa um estado de integração social no qual a linguagem $1 \mathrm{~cm}$ uma significância mínima. Habermas imagina "um estado no qual a linguagem saiu de férias" (1987a, p. 87). O indivíduo não possui existência própria, cle só existe na totalidade. Não ocorreu ainda a diécenciação entre os três mundos (objetivo, social e subjelivo).

Nesta siluação inicial, não existe também diicrenciação entre as esieras da ação teleológica e aquelas da ação comunicaliva; o culto religioso se comporta como uma instiluição total que envolve e integra todas as ações, seja na esfora da família, ou do trabalho social . As estruturas da visão de mundo, as instituições e a personalidade individual ainda não se diferenciaram e permanecem fundidas na consciência coletiva constitutiva da identidade do grupo .

Contudo, com o passar do tempo, a prática cotidiana e o peso cada vez maior dos atos comunicativos vão fortalecendo os processos de alcançar o entendimento em detrimento da tradię̧ão normativa e do sagrado. As conviçéoes passam a relirar sua autoridade cada vez menos da aura do sagrado e cadla ve\% mais de um consenso que não é somente repréduzido mas também alcançado comunicalivamente l lá uma transição da interação mediada simbolicamente para a fala gramalical. Durkheim e Mead vêem este processo como uma linguistificação do sagrado. Nas palavras de Habermas,

... à medida que o polencial embutido na aşão comunicativa é realizado, o núcleo normativo arcaico se dissolve o abre caminho para a racionalização das visooses de mundo, para a universalização da lei e da moralidade e para uma aceleraşão dos processos de individuaşão (19)87a, p. 46). 
Desta foila,

... a comunidade religiosa que foz, pela primeira vor, possível a cooperação social á transformada em uma comunidade de comunicação bascada na pressão para cooporação. A inleração guiada pola norma muda sua estrulura à medida cue as funçõos de reprodução culural, inlegração social, e socialização lou seja, a reprodução simbólica do mundo da vidal passam do domínio do sagrado para acpuele da prática comunicaliva colidiana(1987a, 1). 91).

Por outro lado, Habermas salienta que a coesão social não pode ser garanlida tão somente alravés de processos comunicalivos de busca de enlendimento. Para ele, existem duas fomas básicas de integração de um sistema de ação:

- Integração oblida alravés de um consenso alcançado nomalivamenle ou comunicativamente (Integração social);

- Inlegração oblicla alravés de uma regulaşão não nomaliva das decisões individuais que vai além da consciência clos alores, via mecanismos aulo-regulados como o mercado, ou a hurocracia (Inlegrasäa sistêmica) .

Ora, esta distinção nas formas de integração demanda, por sua vey, uma diferenciação nos conceilos de sociedade. Assim, do pento de vista des sujeitos aluanles, a sociedade é concedida como o munde da vida de um grupo social. Por outro lado,

... da perspectiva de um olsescrvador não (mvolvide), a sociedade só pode ser concelsida como um sislema de açoes lal que cada ação $\mathrm{lcm}$ um significado funcional de acorde com sua contribuição para a manulenção de sistemall labomas, 19)(37a, 1). 117).

Aparlir desta constalação, l labermas propoè um conceilo de sociedade entendida simulaneamente como mundo da vida e sisteme. () fundamen10 deste conceito, ele redira de uma leoria da evolução social que separa processo de racionalização do munde da vida da crescente complexidade clos sistemas sociais. É assim que cle dis. :

Nós vemos a socicedade como uma conlidade (que, no cor-

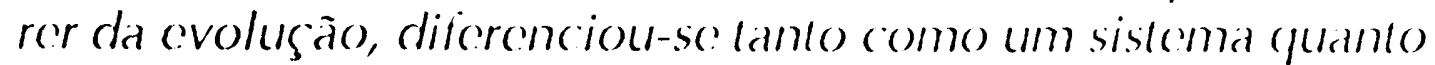
como um mundo da vida.A cuoluşäo sistêmica á medida pelo alumemlo na caparidade de diregia da sociedade, encuanto o eslado de desenvolvimento de um mundo da vida estrullurado simbolicamenle é indicado pola sey)aração da cullura, socicedade e personalidade(1987a, p. 1.52).

Sinteticamente, a sociedade pode, então, ser vista como "Complexos de ação sistemalicamente ceslabilizados de grupos socialmonle integrados" (19)87a, p. 152).

Assim, ele visualiza um processo de evolução social no (pual a racio-

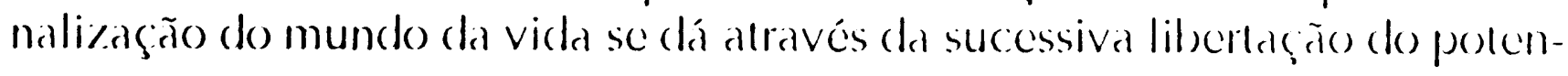


cial de racionalidade conlido na ação comunicaliva e no qual a ação orienlada para o entendimento múluo ganha cada ve\% mais independencia dos contextos nomalivos. Em virtude disto, cada vey maiores demandas são feilas sobre o meio básico da linguagem colidiand, o qual acal)a sobrecarregado, sendo substituído por meios desinguistibicados- os meios dirctores dinheiro e poder - oriundes da esfera sistemica. 1)á-se o desengale, a cisão entre o mundo da vida e o sistema:

Alravés dos moios dimheiro e poder, os subsistemas da economia e do estado são diterenciados fora de eum complexo instilucional estabelecido dentro do mundo da vida; surgem domínios de açäo formalmente organizados /grifo do aulorl pue, em úllima análise, não são mais inlegrados altavés dos mocanismos de concendimento mútuo mas que se desviam dos comextos do mencte da vida e congelam-se num lipo de sociabilidride liverede mormas.

Com essas novas organizaçoes surgem perspeclivas siskemicas, das quais o mundo da vida a distanciade e percehido como um elemente do meio ambiente de sistema. Asorganizaçöes ganham aulonomia alravés de luma demarcargão (fue as meulraliza fionte às estruluras simbélicas do mundo da vida. Tornam-se peculiarmente indilerenles à cullura, à sociedade, e.

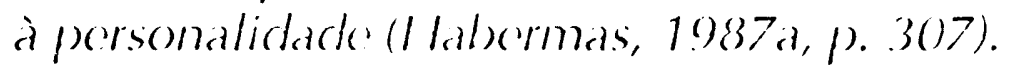

Temos entrio o seguinte quadro : com o desengate entre sistema e mundo da vida que marca a sociedade moderna, o sistema social rompeo horizonte de mundo da vida e distancia-se do saber intuitivo da prálica comunicaliva colidiand.Com a crescente complexidade do sistema social, o mundo da vida é cata ver mais deixado na perileria e perde sou papel de

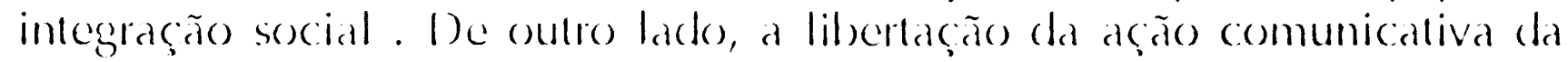

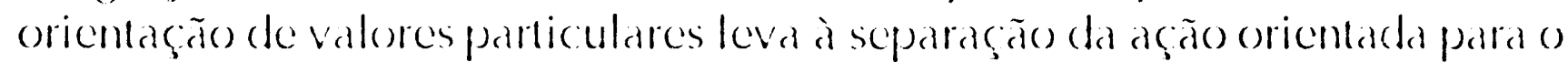
entendimento múluo drepuela orientada para o sucesso,o que abre espaço para cque a coordenaçäe de ações se de alravés de meios de comunicação

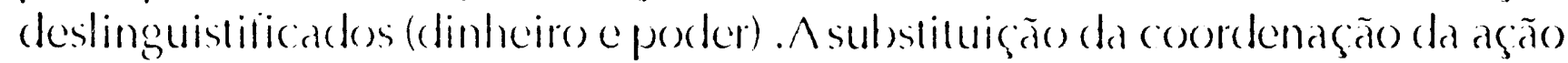
que erd foita inicialmente por meios linguisticos, pelos meios dinheiro e poder, traz como conseyuencia o desalledamento da interação social dos comlextos do munde da vida, o que haz com que este já não seja mais necessário para coordenar a ação . Assim, para llabermas,

...com a instilucionalizaçäolegal do moio monelário (jue marca a comergência do (ap)ilalismo, a açäo orientada para o

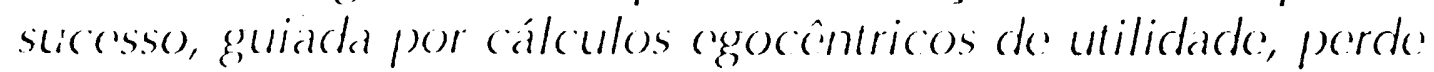

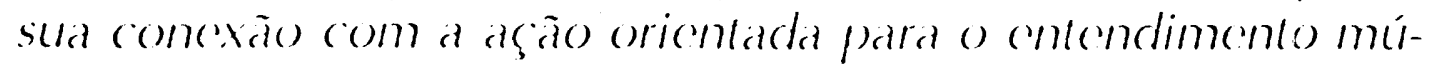

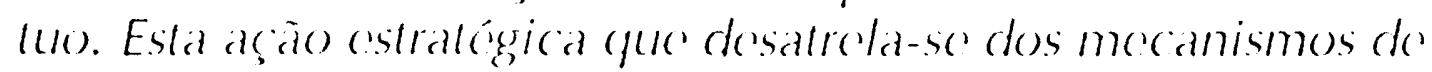
alcancaro ontendimento edemanda por ema alilude objelivante inclusive no (ampo das relacooses imerpessoais a promovida a modele fald lidar meloleggicamente com uma nalureza objelivada ciontificamente. Na estera instrumental, a alividade dirigida a fins, ac) reliral sua legitimidade do sistema ciemliiico, lica liveredas rostriçós nomalivas(19837a, p. 196). 
Chega-se então ao seguinte paradoxo:

A racionalização do mundo da vida lorna possivel a comergência e o crescimento de subsistemas cujos imperativos se vollam definilivamenle conlra o próprio mundo da vida(19837a, p. 186).

Podemos então sintelizar as leses de llabermas em dois pontos:

1- o processo de evolução social é marcado pela crescente racionalização do mundo da vida, a qual implica em progressiva demanda, como agente de coordenação da a(̧ão, pelos mecanismos dealcançar o entendimento mediados linguisticamente, os quais acabam sobrecarregados;

2- Esta sobrecarga sobre os processos comunicalivos, aliada à crescente diferenciação sistêmica, acaba por abrircaminho para que os moios deslinguistificados (dinheiro, via mercado e poder, via administração) burocrálica) assumam cada vez mais as funções de coordenar as ações, alijando para a periferia do sislema os processos comunicalivos mediados linguisticamente. Ocorre uma reilicação das estruluras simbólicas do mundo da vida levada a efeito pelos imperalivos sistemicos (que se lomaram aulosuficionles .

A este processo de reificação de deu o nome de Colonizaçáo do mundo da vida, o qual será responsável por uma série de palologias que alingem as sociedades capilalistas contemporâneas, em especial nos países mais avançaclos. Passemos então à sua análise destas sociedades.

Para labermas, das relaçõos entre sistema e mundo da vida mas sociedades capitalistas contemporâneas, irão ailorar quatro papéis basicos.l as as relações entre o sub-sistema econômico e a esfera privada do mundo da vida (cujo núcleo inslitucional é a família) surgem os papéis de (mpregado do sistema produlivo e de consumidor de produlos. Por oulro lado, das relacẽoes entre o sub-sistema a dministralivo e a esfera pública do munclo da vida (cujo núcleo institucional são as recles comunicativas) temos os papéis de clicnle. da administração pública e de cidadão do Estado (1987a).

Os papéis de empregado e cliente são assumidos nas suas inlerrolações com os sub)-sistemas econômicos e administrativos via mecanismos essencialmente não-valorativos e auto-regulactos (mercade e buroctacia). P'or outro lado, os papéis de consumiclor e cidadão, reierem-se a processos de nalureya essencialmente autoformadora nos quais entram em consideração questões de proferência e orientação de valores e aliludes. A sua nalurezaé definida com referência a domínios organizados formalmente mas não é dependente deles. As normas legais que lhes são relevantesassumem a forma de relações contratuais e dircitos civis. Estes papéis pertencem, portanto, aos contextos do mundo da vida e não podem ser tratados administralivamente ou economicamenle.

llabermas alerla que só portem ser convertidos aos meios dirclores dinhciro e poder aqueles domínios da aşão que precnchem lunģöes econômicas epolílicas. Em contraparlida, esles meios falham completamenle quando aplicados aos domínios da reprodução cullural, inlegração social e 
socialização. Eles não conseguem substituir os mecanismos de coordenação da ação para o múluo entendimento nestes campos .

Quando os mcios dinheiro e poder invadem estas áreas, temos a colonização do mundo da vida . Como afirma Frcilag:

...foi exatamente este processo que lovou ao que Weber chamou de perda de liberdade do homem (..).Foi o que, "mutalis mulandis", Lukács denominou de alienação e Marcuse de unidimensionalização $(1988$, p. 62).

No esquema habermasiano, a colonização do munclo da vida ocorre quando os imperativos sistêmicos retiram os elementos prático-morais e prálico-cstélicos das esferas públicas e privadas da vida. É a monctarização e burocralização das prálicas coliclianas em ambas estas esferas. Ele alirma :

À medida que o sistema econômico sujeita a seus imperalivos as formas de vida do lar privado e a condula de vida dos consumidores a empregados, está aborlo o caminho para o consumismo e para o individualismo exacerbado. A prática comunicaliva cotidiana é racionalizada de forma unilaleral num eslilo de vida ulilitário, esta mudança induzida polos moios dirclores para uma orientaşäo de nalureza teleológicagera, como reacão, um hedonismo liberlo das pressóos da racionalidade. Assim como a esfera privada é solopada e crodida pelo sislema cconômico, tambóm a csfora pública o ć polo sislema administralivo. O esvaziamento burocrálico dos processos de opiniào esponlâneos o de formação da vonlade alorem caminho para a manipulação da lealdade das massas c lorna fácil o desalrelamento entre as tomadas de decisão politicas e os conlextos de vida concretos o formadores do idenlidade(l lalermas, 1987a, 1). 32.5).

Segundo I labermas, este processo é análogo aos mecanismos de dominaf̧ão legal aventados por Wober, nos quais questões prálicas aparecem como questões lécenicas e as demandas por jusliça substamiva são descartadas em favor de uma legilimação via procedimentos.

A infra-estrulura comunicaliva fica enlão ameaçada simultancamente por uma reilicaşão sistematicamenle incluzida (que foi analisada por Lukács) e por um empobrecimento cultural, já que os processos de racionalização cullural se, por um lacko, representaram uma libentação das amarras (da lradição, por outro, deixaram as esferas da cultura aprisionadas nas mãos (le exports, distantes ainda, portanto, das práticas colidianas. Outro ponto fundamental salientado por llabermas é que, com a racionalização e secularização da cullura emprecendida pela burguesia, o amligo poder de coesiono (lo sagrade é perdiclo, e enlão a cullura perde as propriedades que a lomaram capa\% de exercer funçõos ideológicas.

A resposta sistêmica ao fim desta função ideológica da cultura é a lragmentação da consciência do colidiano, que perde seu poder de sínlese.como diz Ilabermas: 
No lugar da falsa consciôncia, nós lomos hoje uma consciência fragmentada que bloqucia o iluminismo pelo mocanismo da reificação. É somonte assim que as condiçõos para a colonização do mundo da vida são dadas (1987a, 1). 35.5).

Nos países de capitalismo avançado, a forma institucional em que se consolida a colonização do mundo da vida é o Estado de bem-estar social embasado na intervenção governamental e na democracia de massas. Segundo flabermas, o marxismo orlodoxo lem grande diiculdade em explicar a emergência desta formação porpue, através de sua leoria do valor, cle vê apenas um dos aspectos da dominação sistêmica, a saber, apuela exercida pelo meio dinheiro. Os maxistas ontodoxos não levaram em conta que o sistema econômico, dirigiclo pelo meio dinheiro, para ser clicaz, deve ser suplementado pelo meio poder .

Ora, no intervencionismo estalal que marca o Estado de bem-estar social o que ocorre é a constanle aluação) (lo sislema administralivo no senlido de contornar as crises que afelam o sistema economico. Ou seja, estamos longe dos tempos de capilalismo concomencial que foram analisades por Marx. É importante ressaltar que, não obstante este processo de interven(ão) se lenhamostrado bastante cficiente no sentide de garantir a solsevivencia do sistema capilalista, ele acaba desencadeande crises de legilimagãa uma vez que as crises de nalureza economica lomam-se não sé) administradas mas acabam lambém deslocadas para o sistema administralivo. I)esta foila, com o avanço das disfuncionalidacles do sistema de livre mercade cue anoaçavam a sua própria existência com crises sucessivas, a intervenção estalal lornou-se cada ve\% mais imprescindivel. Ora, este ialo entra em oposicão) frontal com a ideologia do Estado liberal, com a idéia de uma sociedade civil emancipada que neutralize o poder (l labermas, 1987 c). Ocome uma repolitização do sistema econômico, com a demanda de meraniomos do legilima(̧ão equivalentes aos que existiram em sociedades frécapilalistas. Contudo, o seu restabelecimento é impossivel porque, de um lade, as tradições já se dissolveram e, por outro, has sociedades industriais os resultados da emancipação burguesa relalivamente à domina(ẽão polílica imediala (os dircitos fundamentais (do homem e o mecanismo das cleiciones gerais) impe(em qualquer relorno às formas pré-burguesas (1 labermas, 1980).

Os limiles do intervencionismo estalal ficam claros quando analisamos as sociedades industriais desenvolvidas do ocidente e o impacto yue esta inlervenção causa nas decisões dos investimenlos privados. Assim, os custos maiores em salários, impostos e encargos labalhistas lôm levado as empresas a intensilicar seus investimentos em capilal, visando uma maior produlividade, o que implica em queda no nível de emprego com roflexos na estrulura liscal. Ademais, a forle presenca do Estade lem um cieito psicológico no sentide de desestimular investimentos. () yue se constala então é que há um limile à ação (k) Estado, e mesmo onde cla representou alguns ganhos à qualidade de vida, como nos países capjitalistas desenvolvides, lica clara a sua impolência em assegumar garantias fundamentais como, por exem-

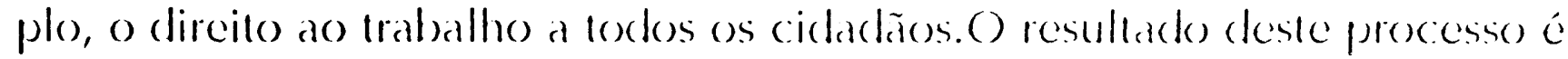


que o Estado corre o risco de perder sua base social que tende a se alinhar com posições mais conservadoras (discurso neo-liberal) em oposição aos segmentos da população mais desiavorecidos (1 labermas, 1987b).

Se na esfera do intervencionismo estatal na economia, o Estado de bem-estar enfrenta problemas, a situação se complica ainda mais no que toca à sua legitimação na forma de democracia de massa. Aqui, a colonização do mundo da vida é ainda mais crílica. Isto porque o poder legal advindo de um sistema administrativo depende, em última análise, de uma legilimação de ordem política. Em princípio, somente procedimentos democráticos de iormação de vontade podem gerar legitimação num mundo da vida racionalizado e com alto nível de individuação da personalidade. Este fato, evidentemente, entra em contradição com os imperativos sistemicos. Por isso, segundo Habermas, "entre capilalismo e democracia existe uma tensão indissolúvel ; em ambos, dois princípios opostos de integração socictária competem pela primazia" (1 labermas, 1987a, p. 345). Esta tensão transparece, por exemplo, na esfera da opinião pública que envolve tanto um polencial de formação livre da vontade quanto os elementos de manipulação política e de produção antiiicial de lealdade das massas, limilando o papel do cidadão a um mero eleitor com poder de decisão política restrito.

Os limites do Estado social iicam ainda mais evidentes no que se refere à sua intervenção na própria vida dos cicladãos onde visa garantir a justiça social.Se, num primeiro momento, esta aluação social do Estado representou ganhos cietivos na qualidade de vida da população, a hipertrofia desta intervenção e a burocratização que a acompanha, com seus cleitos de tratamento impessoal, nomatização e vigilancia excessiva, acabaram vollando-se contra seus beneficiários. As formas burocrálicas de administração são incapazes de alender às demandas por emancipação. Problemas sociais são tratados num viés legalisla, questões calcadas na história de vida e em siluações concretas são submelidas a um alto nível de abstração, tratadas de forma administrativa e referenciadas lão somente em compensações linanceiras. Há uma tolal desconformidade entre o lipo de demanda e o serviço ofereciclo pelo Estado de bem-estar social (1987a).

Quanto mais o Estado social expande sua rede assistencial sobre as esicras da vida privada, maiores os efeitos colaterais patológicos de uma juriditicação que envolve tanto a burocratização quanto a monelarização de esieras centrais do mundo da vida.

Esla juriditicação atinge as áreas de proteção ambiental, segurança nuclear e probeção de dades, assim como os campos do lazer, da cultura, do turismo e recreação que, cada vez mais, adequam-se às regras da economia de mercarto e consumo de massa $\wedge$ própria hamília burguesa e a escola encquadram-se ante os imperativos sistemicos .

l labermas se preocupa de forma particulamente intensa com a intervengão burocrática e o controle judicial da escola e da lamília. Para cle,

...de iorma alguma, família e escola se constiluem en-

quanto esforas do aģäo formalmente organizadas. (...)Nestas 
esferas do mundo da vida, nós encontramos, anterior a qualuper legalização, normas e contextos de ação que, por necessidade. funcional, são baseados no entendimento múluo como um mo:canismo de coordenaşão de aşão (1987a, p.369).

Os processos formativos que têm lugar na familia e na escola, e que acontecem pela via da ação comunicaliva, devem ocorrer independentémente de qualquer regulação legal. $\wedge$ lei deve ter um papel meramente complementar nas áreas de ação socialmente integradas .

No caso da família, Habermas cila o exemplo da legislação que regula os direitos da criança, que às vezes visando prolegế-la da violencia dos pais, cria uma tecitura legal que produz uma nova rolação de dependência. Sacm os pais, entra o Estado. ^ssim, para cle, o que,

...à primcira vista, é algumas vozes apresentado como um instrumento para romper as estruluras de dominaşão no interior da familia, prova, frente a um exame mais delalhado, sor lambém um véculo para uma nova forma de dependência(1987a, p. 37()).

Habermas mostra a inadequação do sistema legal para lidar com este lipo de questão, uma vez que "é o próprio meio da lei que viola as estruluras comunicativas da esfera que foi legalizada" (1987a, p. 370).

Analogamente, no caso da escola, ele atirma:

A proteção dos dircilos dos alunos o pais contra as medidas educacionais (como promoşão, ou näo promoşäo, cxames, testes, ele) ou contra alos da escola e do departamento de educação que restringem direitos básicos (ponalidades, disciplinas), ó ganha ao custo de uma legalização o burocratização que penetram fundo no processo de ensino a aprendizagem(1987a, p. 371).

Isto porque, de um lado, este processo provoca uma solbrecarga nas agências governamentais e, de outro, como no caso da lamília, o meio "Ici" entra $\mathrm{cm}$ confronto com a forma em que transcorre a atividade educacional. Este processo de excessiva regulamentação coloca em risco a liberdade pedagógica e a iniciativa do professor, assim como leva à despersonalização, inibição da inovação, perda de responsabilidade e imobilismo.

Para Habermas, a saída desta siluação passa por,

...como no caso da família, (..) desregulamentar e sobreludo desburocralizar o processo pedagógico. 1 conslituişão de. uma legislaşão escolar deve embasar-se em procedimentos de. lomada de decisão que considere todos arqueles envolvidos no processo pedagógico como tendo capacidade de representar sous próprios interesses e de regular seus atos por inicialiva própria(1987a, p. 372).

Estas colocações de tabermas apontam para a importância de mecanismos de decisão, como é o caso dos Conselhos de Escola, ou Colegiados 
que buscam colocar o poder de decisão, no âmbito da escola, nas mãosda comunidade escolar em detrimento do poder burocrático. Nós voltaremos a este tópico mais adiante. Antes, contudo, vejamos como, na visão de I labermas, o Estado social cnirenta as patologias que adtêm da colonização do mundo da vida.

Baseando-se em Chaus Oife, Habermas mostra que, frente a estas questões, só resta ao Estado de bem-estar a estratégia de evilação dos problemas cronicos. Enesla atividade preventiva, o Estado se restringe à ação administrativa, à execução de lécnicas que vișam garantir o funcionamento de um sistema regulado. O problema porém é que os problemas não são técnicos, mas práticos, e não se encontram na estera da "ação racional teleológica", mas da "ação comunicativa". A tálica utilizada pelos que detêm o controle do sistema é a de despolitizar as massas, climinando os conteúdos prálicos dos problemas, visando transiormá-los em lécnicos e que, como lal, devem ser resolvidos cientificamente. Está aberto o campo para a tecnoburocracia (I labermas, 1987c).

Estas ações preventivas não conseguem conludo eliminar estes problemas. Citando Ofice, l labermas diz que as zonas de conilito surgem entre as necessidades que ficam na periieria do (ampo de aşão estatal e aquelas centralmente localizadas. Assim, surge uma disparidade entre o nivel efetivamente institucionalizado e as potencialidades reais de desenvolvimento lécnico e social. Como exemplo, cita o estupendo avanço dos meios de produção e defesa em comparação com a estagnação dos serviços de saúde, educação; ou a grande elicácia do planejamento nas áreas fiscal e financeira, comparada com o caos (lo planejamento urbano (1987c).

Com este processo, há um destocamento das zonas de conilito da esfora da luta de classes (como ressalta a leoria marxista) para os âmbitos subprivilegiados da vida. Situam-se neste caso os contlitos raciais nos EUA ou na Europa, por exemplo. Todavia, uma vey que estes grupos nãe são classes sociais e o sistema não vive (depende) do seu trabalho, o seu potencial de êxito revolucionário é restrito (1987 ce e 1980).

Habermas acredita que uma nova zona de conilitos não virá da luta de classes, ou destas disparidades entre centro e periferia do sistema, mas surgirá exalamente do sistema de opinião pública, administrado pelos meios de comunicação que é onde atuam os mecanismos de despolitização das massas, os quais ocultam as diferenças entre as questẽes lécnicas de regulação do sistema e as possibilidades reais de emancipação existentes no marco instilucional (estera da ação comunicativa) (1987c).

Concluindo, podemos dizer então que o grande dilema do Estado de bem-estar é que ele visa a integração social alravés de mecanismos que só desintegram as relaçöes de vida.A assistencia lísica, psico-social e emancipatória requer modes de operação, criberios de racionalidade e formas organizacionais que estão fora dos domínios da administração burocraticamente estruturada (1987a).

Haverá então, l labermas, chegado aos mesmos dilemas da dialélica 
negativa de Adorno e Horkheimer, ou àqueles da análise webcriana ? Ou seja, será que o desenvolvimento da razão acaba gerando inexoravelmente os elementos que levam à destruição de lodo o seu potencial emancipalório c iluminista?

I labermas acredita que não, porque, ao contrário destes autores, de não confunde o descnvolvimento da razão instrumental como senclo o próprio processo de racionalização sociclária. Esla confusão levou Wober, Adorno e Horkheimer a buscar a esponlancidade livre da reilicação em poderes irracionais (carisma, arte e amor). Na verdade, o processo narrado por esles aulores é consequência não do processo de racionalização sociclária mas da colonização do mundo da vida pelos imperalivos sistêmicos. Alarefa que se coloca então é a reconquista dacpuclas estruluras simbólicas clo mundo da vida (cullura, sociedade e pessoa) pelos mecanismos que coordenam a ação) através da busca do entendimento. Segundo l labermas:

...só a racionalidade comunicaliva reflelida numa aulocomprecnsão da modernidade, oferece uma lógica inlerna (..) para resistir contra a colonizaḑão do mundo da vida pola dinâmica interna de sislemas aulónomos(1987a, 1). 33.3).

Diante do esgotamento do Eslado social, Habermas vê três atiludes possíveis. De um lado, estão os legilimistas do Estado social que lusscam consolidar o nível já alcançado, buscando restaurar o equilíbrio entre intervenção estatal e modernização da economia de mercado.l)e oulro, estão os neoconservadores (representados, por exemplo, nas polilicas descrnvolvidas nos governos Reagan e Talcher) que partem para o alaque ao Estade social, embasados no discurso neoliberal. Um terceiro grupo assume uma linha de crílica ao crescimento como um l cem em si. São grupos variados c helerogêneos (velhos, jovens, mulheres, desempregados, homossexuais) o o yne os une é uma recusa à visão produlivista que permeia o pensamento tanto dos legilimistas do Estado social quanto dos neoconservadores. Eles $10 \mathrm{~cm}$ uma postura ambivalente ante o Estado social e entendem que o mundo da vida está ameaçado lanto pela mercantilização (dinhoiro) quanto pela burocrallização (poder). Falla a este grupo, porém, um programa allernalivo, cles se limitam a uma postura negaliva, à "(ilande Recusa" (19877)).

l habermas entende que somente este terceire grupo lom condições de sair da alitude defensiva que compartilha com os demais. Para lanto, contudo, sua aluação deve ser no sentido de levar o projelo do Eslade sociala um nível mais alto de reflexão e o primeiro passo nesta (liref̧ão é (que o lrabalho) deixe de ser o cixo de referencia. Em seguida deve haver um comlrole social e ecológico da economia de mercado que, deixada à sua própria sorte, lem levacto a disparidades sociais cada vez mais grilantes, com alrasos e involuções econômicas (como a fome no $3^{\circ}$ Mundo), colocande cm risco a própria exislência do homem sobre a terra em virtude da degradação ambiental . Não obstante, esta intervenção no mercado (que não deve ser eliminado), precisa aconlecer através de mecanismos inclirelos, "parlinde de fora, solore os mecanismos de auto-orienlação do sistema" (l labermas, 1991, p. 57).

Aém do mercado, opróprio Estado intervencionista precisa ser, agora, 
socialmente controlado.

Para que estes dois processos ocorram, é necessário conludo, segundo l labermas, haver uma "mudança da relação entre os espaços públicos autônomos, de um lacto, e, de outro, os setores comerciais orientados pelo dinheiro e pelo poder administralivo" (1991, p. 57).

As sociedades modernas dispõem, para l labermas, de thês recursos que podem salisfazer suas necessidades de governo : dinheiro, poder e solidariedade. O poder integrador da solidariedacle deve servir de barreira eficaz ao poder do dinheiro e ao poder administralivo, de lal iorma que o mundo sistêmico não invada o mundo da vida.

Nesta redefinição de posiçoes, as decisões passam a nascer de um processo de reflexão onde se garante a livre discussão dos lemas e propostas de solução aos problemas apresentados, garantindo-se simultancamente eficácia c responsabilização dos parlicipantes pelas decisões lomadas . Como alirma llabermas, "o poder gerado de mode comunicativo pode aluar sem intuito de conquista, solme as premissas dos processos de valorização e decisão da administraşão pública" (1991 p. 58). Ele garanle o fundamento das ações que opoder administralivo pode alé execular de forma instrumental.o pressuposto deste agir comunicalivo é contudo a garantia de uma formação radicalmente democrálica de opinião e vontade.

Além disto, l tabermas entende que o nível dos problemas enfrentados pelas sociedades desenvolvidas só encontrará solução pela via de uma moralização dostemas públicos, algo que, como vimos, o sistema lecnocrálico insiste em evilar, numa postura de adiar as solucióes estruturais e que lem, cada vez mais, colocado em xeque a sua própria existência .

Problemas comos a ameaca nuclear, os gastos com amamentos, a obsolescencia programada, opreconceilo contra as minorias e a miséria no 30 mundo, não são técnicos e não encontrarão solução na alual distribuição depoder. Eles sópoderão ser entrentados

...pelo vices de uma moralização dos temas, por uma generalizasão de interesses operada de modo mais ou menos discursivo em espaços públicos não obstruidos de culluras polilicas liberais (l labermas, 1991, p. 59).

Sintedizande, l labermas propõo uma organização onde as esicras públicas autônomas alcançariam uma combina(̧̃äo de poder e autolimitação, aluando sobre os mecanismos de auto-regulação do Eslado e da economia, visande uma formação radicalmente democrálica da vontade, lende como pressuposto um destocamento das encrgias ulópicas (lo campo do lrabalho para o da comunicação. () conleúdo ulópjico desta sociedade da comunica(rão eslá em garantir condições hásicas para uma prálica comunicaliva colidiana cue propiciaria as condiçoes para os próprios participantes - de acordo com scus próprios interesses - realizarem uma vida melhor (1 labcrmas, 1987b)).

labermas, alerta contude que

... L ma solnerania popular assim processada não poderá operar lambím som a relaguarda de uma cullura polílica cque. 
the venha em apoio, sem as manciras de pensar (gesinnungen) de uma população habiluada à liberdade política : não há formação da vontade política sem o auxílio de um mundo da vida racionalizado(1990, p. 111).

Finalmente, adverte cle para os riscos de se cair numa "religião civil" c proclama uma " cultura de massas, profana, irrestrita e igualitária "(1990), p.113).

\section{HABERMAS E A ORGANIZAÇÃO}

Nesta altura do trabalho, podemos então tentar esquemalizar quais seriam os principais elementos de um modeloorganizacional baseado na leoria da ação comunicativa :

1- Liberlação do mundo da vida dos imperativos sistêmicos, mediante uma desregulamentação e desmonelarização de suas estruturas (cultura, so)ciedade, pessoa). Na prálica, isto implica cm :

a- Luta contra os imperativos financeiros e burocrálicos que regem a produção tanto cultural quanto cientílica; controle público solbre os meios de comunicação de massa com vistas a garantir uma formação democrálica da vontade ;

b- Enxugamento progressivo da tecilura legal que rege as relações entre pessoas enquanto componentes de uma estrutura social normalivamente legitimada.Preocupar-se mais com o conteúdo das normas do que com sua processualística.Promover uma moralização dos temas públicos, via discussão polílica, aberta a lodos;

C- Restringir ao máximo a legislação sobre a familia e a escola e empreender a sua desburocralização radical, visando assegurar a formação de uma personalidade autônoma;

2- Manutenção dos sistemas econômicos e administrativos guiados pelos mecanismos do mercado e da administração burocrálica mas submetidos a controle externo;

3- Este controle será exercido por associações espontancas (vemos aqui as Organizações Não-governamentais, ONCis), organizadas na esicra dos espaços públicos autônomos (vemos aqui a presença dos Conselhos). Fica claro que sua força não advirá de mecanismos formais de poder mas de sua legitimidade;

4- Valorização de mecanismos de deliberação coletiva que estimulem o entendimento e não a mera conquista do poder (por exemplo, deliberação por consenso e não por volação).

Se conseguimos captar acima, de fato, o espírilo da proposta habermasiana, o que se constala é que este autor não propõe a destruição do aparato estatal-burocrálico, ou do mercado. No fundo, a nosso ver,o que de sugere é uma democracia processual, uma "soberania em procedimento", 
na qual os mecanismos de ação do mercado e do poder administrativo serão controlados no âmbilo de conselhos populares (espaços públicos aulônomos ) no qual intervêm as associa(ẽoes não governamentais e que se valem de processos comunicalivos de busca do entendimento.

\section{Conclusão}

Neste breve esboço da leoria da ação comunicaliva de Jürguen l labermas esperamos ler moslrado que esla leoria, alravés do seu conceilo de sociedacle em dois níveis, Sislema (esfera regida por mecanismos dirclores auto-regulados como o mercado e o poder administrativo) e Mundo da Vida(esfera regulada pela busca do entendimento alravés de procedimentos mediados linguisticamente) e, em particular, alravés de seu postulado de colonizaçäe do mundo da vida pelos imperalivos sistemicos, oferece uma chave adequada para interpretarmos a sociedade capilalista contemporânea com suaspalologias e contradições. Acém de propiciar um diagnóstico acuracto dos problemas organizacionais presentes no alual eslágio de desemvolvimenlo do modo de produção capilalista, esta leoria aponta para o papel fundamental clesenvolvido por mecanismos como os conselhos populares, organizados encuanto espaços públicos autônomos, no sentido de servir de barreira a colonização do mundo da vida pelos imperalivos sistêmicos. E é dentro desla perspecliva que vemos a aluação dos Conselhos de Eclucação, Saúde e Meio Ambienle, enlre ouldes, que se espalham pelo país.

Com relação à escola, a teoria da ação comunicativa ajuda a conlen(ler o seu processo de burocrali/ação, assim como a iniluência sancadora exercida por mecanismos pue lrazem o pexter de decisão sobre os seus destimos para as mãos da comunidade escolar, como é o caso dos conselhos escolares, os (quais, não obstante, como mostram os estudos de campo, lambém solrem os cicilos dos constrangimentos sistemicos (Paro1992, Passos, CarvaIho e Silva, 1988 e Pinco, 1994).

Entendemos que a leoria da ação comunicaliva fornece, não só uma explicação para a existência de conselhos com participação popular, que intervêm na lixação de diretrizes de polílicas públicas e de investimentos privados, mas mostra lambém que a consolidação destes espaços públicos autônomos, onde aluam os diversos grupos da sociedade civil, é condięão básica para a solução de uma série de palologias que marcam as sociedades capilalistas contemporâneas. $\wedge$ luz da análise habermasiana, a existência desices fómuns de discussão e deliberação nasce, não de um alo de vonlade de um grupo de individuos que lubam por justiça e liberdade, mas como uma necessidade que encontra seus fund damentos nos próprios processos de racionalização socictária. Ao questionar oparadigma da razão instrumental como o único padrão de racionalização possivel, inlroduzindo o conceito de razão comunicaliva, l labermas realiza um salto paradigmálico com profundas implicaçẽos para a leoria da administração.Se, como de aponta, no âmbito do munclo da vida, onde ocorrem os processos cruciais de produção e laans- 
missão cultural, de socialização e de iormação da personalidade individual, a ação deve necessariamente ser dirigicla por processos comunicalivos de busca do entendimento e não altavés de meios auto-regulados, como o mercado ou a administração burocrática, como sói ocorrer alualmente, isto siggnifica a necessidade de mudanças profundas nas formas de gestão destas áreas, mudanças estas que implicam na introdução de mecanismos de decisão que levem em conta a participação de lodos aqueles que solrerão os cícilos desta ação.

Esperamos, portanto, neste breve arligo, ter demonstrado as potencialidades da teoria da ação comunicativa de l labermas como referencial teórico para os estudos organizacionacionais e, temos certera, que novos estudos nesta vertente aqui estoogada, poderão trazer contribuições imporlantes a todos aqueles que lutam pela construção de uma sociedacte que não seja guiada pelo poder do dinheiro, ou da burocracia, como hoje, mas por homens emancipados que vêem a diversidade, não como um ônus mas como um trunfo fundamental para a sobrevivência da civilisaçróo.

\section{REFERÊNCIAS BIBLIOGRÁFICAS}

Aragão, L.M. de C. (1992). Razão Comunicaliva e leoria social crílica com Jürgen I labermas. Rio de Janeiro, Tempo Brasileiro.

Freilag, B. (1988). A teoria crílica:ontem o hoje. São Paulo, Brasiliense.

I labermas, J. (1980). A crise de legilimaşão do capilalismo lardio. Rio de Janciro, Tempo Brasileiro.

I labermas, J. (1984). The theory of communicalive action. Vol 1. Reason and the rationalization of socioly. Boston, Beacon Press.

I labermas, J. (1987a). The theory of communicalive action. V'ol 2. Lifewerld and sistem : A crilique offunctionalist reason. Boston, Beacon Press.

Habermas, J. ( 1987b)). A nova instransparencia. A crise do Estade de bemestar social e o esgotamento (las encergias utópicas. In Noves Estudes (cobrap. São Paulo, 18: 103-114, Selembro.

I labermas, J. (1987c). Técnica o ciôncia como "idteologia". Listrad, Ediçũes 7() .

Ilabermas, J. (1990). Soberania popular como procectimento. In Novos Esludos Cobrap. São P'aulo, 26: 10()-113, Mar(co. 
I labermas, J. (1991). Que signilica socialismo hoje? Revoluşão recuperactora e necessidade de revisão da esquerda. In Novos Esludos Cobrap). São Paulo, 30:43-61, Julho.

MeCarthy, T. (1984). Introdução à obra The Theory of communicalive action, Vol 1. de J. Habermas. Boston, Beacon Press.

Paro, V.II. (1992). Parlicipação popular na gestão da escola pública. São Paulo, Faculdade de Educiação da USP). (tese de livre docência)

Passos, I; Carvalho, M. e Silva, Z.I.F. (1988). Uma experiência de gestão colegiada. Cadernos de Pesquisa, São Paulo, Fundação Carlos Chagas, (66): 81-94, Agosio.

Persson, L. C. K. (1992). Tooria da aşão comunicativa o esludos organizacionais: (lma reflexão crítica. São Paulo, FCiV-EAESP. (disserlação de mestrado)

Pinto, J. M. R. (1994). Administraşão o Liberdacke: ( /m estudo do Conselho de Escola à luz da leoria da aşão comunicaliva de Jürgen Habermas. Campinas, Faculdade de Educação/UNIC.AMP?. (Iese de doutorado)

\section{ABSTRACT}

It's our aim lo present in this paper, he basic concepts from Jürgen I labermas' heory of communicalive aclions, as well to develop some inferences of this theory for the administration sludy, specialy the school one.

Kay Words: Theory of communicative action, Habermas' theory applicad at administration, school councils, democratic administration.

Palavras Chaves: Teoria da agao comunicativa, Teoria de Habermas aplicada a administrasian, consolhos escoldres, gestao democrálica. 